\title{
The COVID-19 Pandemic and Sustainable Life of Korean Adolescents: Exploring Gender Differences
}

\author{
Seunghee $\mathrm{Yu}^{1}$ and Chung Choe ${ }^{2, *(\mathbb{D})}$ \\ 1 Department of Social Welfare, Sungkyul University, Anyang 14097, Korea; shyu398@hotmail.com \\ 2 Department of Economics, Konkuk University, Seoul 05029, Korea \\ * Correspondence: choechung@gmail.com
}

check for updates

Citation: Yu, S.; Choe, C. The COVID-19 Pandemic and Sustainable Life of Korean Adolescents: Exploring Gender Differences. Sustainability 2021, 13, 8821. https://doi.org/10.3390/su13168821

Academic Editor: Haywantee Ramkissoon

Received: 29 June 2021

Accepted: 4 August 2021

Published: 6 August 2021

Publisher's Note: MDPI stays neutral with regard to jurisdictional claims in published maps and institutional affiliations.

Copyright: (c) 2021 by the authors. Licensee MDPI, Basel, Switzerland. This article is an open access article distributed under the terms and conditions of the Creative Commons Attribution (CC BY) license (https:// creativecommons.org/licenses/by/ $4.0 /)$.

\begin{abstract}
To ensure that adolescents continue to lead healthy, well-adjusted lives_- "sustainable lives"-after the COVID-19 pandemic, it is important to examine the latter's impact on various aspects of their lives compared to the socio-cultural context before the outbreak. This study used national representative data on Korean adolescents to analyze the impact of the pandemic on adolescent life from various perspectives, with a focus on gender differences. Our findings confirm that during the pandemic physical activity and sitting time for study purposes decreased, while sleeping and sitting for purposes other than studying increased, with more pronounced changes among girls. Drinking and smoking decreased and boys experienced greater decreases. The findings also indicated that the pandemic generated positive outcomes for mental health: stress, sadness/despair, and suicidal ideation decreased, which was counterintuitive to our general expectations, with a greater impact seen among girls.
\end{abstract}

Keywords: COVID-19; pandemic; adolescents; sustainable life; gender differences

\section{Introduction \\ 1.1. Background}

Since the beginning of 2020, COVID-19 has quickly spread around the world, with the World Health Organization declaring it a pandemic in the spring of that year [1]. Faced with numerous deaths and infections worldwide, most countries have taken extensive prevention and lockdown measures to curb the spread of the virus. Although children and adolescents were less directly affected by COVID-19, with most displaying mild physical symptoms or remaining asymptomatic [2,3], its impact on their health-related quality of life is not fully understood.

Adolescents have experienced massive changes in their daily lives, including school closures, home confinement, and social distancing requirements [4,5]. Direct face-to-face contact has been restricted, with most of the activities that typically occupy adolescents' lives-schooling, leisure activities, and socialization with peers-shifting to online platforms [6]. The COVID-19 pandemic has not only disrupted academic learning but has also impeded the acquisition of many social skills, such as competence, team spirit, leadership, harmony, and many more, which cannot be learned fully through digital platforms [7].

Schools are making up for learning deficits through online classes, but not all students take advantage of this "untact" education due to a lack of resources and expertise. Online learning requires the involvement of parents, teachers, schools, and school administrators in the learning process for an extended period [8]. School closures and limited opportunities for outdoor activities have been linked to several negative results among adolescents, such as reduction of physical activities, increased screen time, sleep disturbance, and unhealthy weight gain $[6,9,10]$. Adolescents in the United States reported more delayed sleep/waking-up behaviors, longer school-night sleep duration, and less daytime sleepiness during COVID-19 compared to before it [11]. 
Experiencing the pandemic during such a critical developmental period in life may strain adolescents' psychological well-being [12]. For instance, the current crisis places them at risk of experiencing social isolation, fear, anxiety, stress, and depression [13]. One study revealed that adolescents, particularly high school seniors, were distressed and concerned about the future due to being away from school and friends [14]. Chinese students in Hubei province demonstrated high levels of anxiety and depression after 30 days of lockdown enforced to curb the spread of COVID-19 [15].

Scholars also worry that the COVID-19 pandemic may increase risky behaviors such as substance use and suicide [16-18]. People who are isolated and stressed during the COVID19 pandemic may use substances to cope with their negative emotions [19]. However, given that adolescents generally use substances for social enhancement and are less likely to do so by themselves, this behavior may be limited during the pandemic [20].

Dumas et al.'s [16] research, which examined substance use among 14- to 18-year-old adolescents before and after the social distancing order in Ontario, Canada, suggested that the pandemic had a complicated impact on adolescent substance use. The percentage of adolescents who engaged in binge drinking, vaping, and cannabis use significantly decreased post-shutdown; however, no significant change was found in the ratio of alcohol users and the frequency of alcohol and cannabis use increased. In a study of adolescents in Northern California, the overall prevalence of e-cigarette, cannabis, or alcohol use did not meaningfully change with the onset of stay-at-home restrictions [21].

The impact of the COVID-19 crisis on adolescent suicidality is not yet conclusive. An increase in mental health problems during the pandemic may lead to an increased risk of suicide [22]. However, [4] reported that suicide rates among Japanese adolescents between March and May 2020, during the period of school closure, decreased slightly. Fortgang et al. [23] found a significant longitudinal increase in suicidal thinking among adults during the COVID-19 pandemic, positively associated with social isolation. In their study, adolescents revealed increases in isolation but not suicidal thinking during the pandemic. Although exposure to traumatic events, such as a natural disaster, disease, accidents, and the loss of a loved one, is a known risk factor for developmental complications in adolescents, there is growing evidence indicating that these events can lead to positive changes [24-26]. The traumatic experience can shatter individuals' pre-traumatic assumptions about themselves, others, their relationships, and the world and reduce positive illusions to provide a window of realism through which they can recognize what is most important in life [25]. Positive psychological changes experienced as a result of struggle with hardships include changed self-perception (e.g., an increased sense of personal strength, ability to survive, and capacity to endure), improved interpersonal relationships, a changed philosophy of life (e.g., positive changes in life priorities and a greater appreciation for life), and a richer existential and spiritual life [26,27]. A break from school attendance, academic work, extracurricular activities, and problematic peer interactions may temporarily relieve the stress and burden of a busy and complicated life. In this context, the COVID-19 pandemic experience might enable a more sustainable life by encouraging us to look back on our lives before the outbreak and identify ways to improve after the danger has subsided. A Swiss longitudinal study found an increase in adolescents' stress and anger levels, but a decrease in internalizing symptoms (depression, anxiety, suicidal ideation, and self-injury) during the pandemic [12].

Stay-at-home orders that lead to school closures and social distancing measures have increased family time. Adolescents spend more time with their parents; for instance, having meals together, engaging in shared activities, paying attention to each other, and building more effective communication [28]. Parents may closely monitor their children, which could reduce risky behaviors such as substance use [29]. They also may buffer their children's stress and help them cope with their negative feelings during the pandemic [30]. Thus, the impact of the pandemic on adolescents' lives comprises both positive and negative aspects, and various empirical studies are needed to investigate these associations. 
Before the outbreak of the pandemic, the government had implemented policies for the sustainable lives of young people — a stable and well-adjusted transition into adulthood [31]. In terms of education, high-quality education with effective educational outcomes, the provision of vocational education opportunities to obtain good jobs, and a guarantee of the education rights of young people were implemented. In terms of heal thy lives, policies were implemented to ensure adequate sleep, increase physical strength, manage mental health, provide sex education, and prevent substance abuse. Family counseling, supervision and improvement of harmful environments, protection and treatment of adolescents exposed to harmful environments, and the creation of a safe media-use environment were implemented to create healthy families and communities. To ensure adolescents' sustainable lives during and after the pandemic, it is necessary to examine these policies in light of the changes COVID-19 has brought to their lives.

\subsection{Heterogeneity in the Impacts of COVID-19}

Recent studies have noted that the COVID-19 crisis may affect adolescents differently depending on their socioeconomic characteristics [32,33]. Given the heightened gender differences reflected in physical changes and mental health during adolescence [34], it is particularly necessary to consider gender differences when analyzing the pandemic's impact. During adolescence, girls are more interpersonally oriented than boys and are more vulnerable to internalizing problems such as depression and anxiety [35]. Conversely, boys are reportedly more involved in externalizing problems than girls, which can lead to increased levels of delinquency and substance use [36,37].

Overall, boys are more active than girls $[38,39]$. There are gender differences in sedentary behavior: boys are less sedentary, watch more television, and play more computer and video games than girls, whereas girls tend to spend more leisure time reading and chatting online than boys $[40,41]$. Girls also tend to have poorer sleep quality and shorter sleep duration than boys [42-44]. In [45]'s study, females showed higher levels of emotional distress before and during the pandemic (perceived stress, internal symptoms, and anger) than males. They also experienced higher levels of lifestyle disruptions (daily routine, work, education, and family) and hopelessness compared to males. Given that girls report higher levels of mental health problems in adolescence than boys, the pandemic may be particularly detrimental to girls' psychological functioning [12]. However, in general, boys may have experienced more restrictions to physical activity and substance use (e.g., alcohol and smoking) during the pandemic because they are more involved in such activities than girls [46-48].

The impact of COVID-19 on people may vary based on the socio-cultural background of each country. Since the outbreak of the virus, South Korea has implemented strong quarantine guidelines and social distancing, including the mandatory use of masks, bans on large-scale group gatherings, encouraging work at home, school closures, and limiting store hours. Korea has an active culture of nighttime activities, such as night shifts, after-work dinners, leisure activities, and students' after-school learning through private educational institutes. Therefore, social distancing due to COVID-19 has brought about enormous changes in Koreans' daily routines.

In the case of adolescents, not only have most school classes switched to an online format, but the private academies where most Korean students participate after school have been closed for an extended period due to the pandemic. Compared to before the outbreak of the virus, students have more time to stay at home, study online, and work on the school curriculum on their own. Parents have also reduced their activities at night and are spending more time at home with their children. Although many people have focused on the negative impact of the pandemic on Korean society (e.g., increased levels of depression and anxiety, economic difficulties, and increased child abuse) [49-51], the question remains as to whether the virus has only had a negative effect on Korean adolescents.

While it is clear that enforced social distancing measures have constrained our freedom and put the brakes on economic growth, the crisis is also an opportunity to look back 
at issues we have overlooked: pollution, family relationships, and overly busy and competitive lifestyles. To encourage sustainable living among adolescents after the pandemic, it is crucial to analyze the impact of the COVID-19 crisis on various aspects of their lives compared to the socio-cultural context before the pandemic.

\subsection{Sociodemographic Characteristics and Adolescents' Lives}

Age and socioeconomic status (SES) are generally reported to significantly affect adolescents' lives. As age increases, physical activity decreases and sedentary time tends to increase [52,53]. Older adolescents have more evening activities, go to bed later, and sleep less than younger adolescents because of increased pressure from academic, social, and extracurricular activities [54]. Adolescents' developing brains and hormonal changes make them more vulnerable to depression and more likely to engage in risky and thrill-seeking behaviors, such as delinquency and substance use, than other age groups [55]. Older students can have more general mental health symptoms because adolescents experience increased academic and social pressure as they progress from junior high school into high school [56].

Adolescents from higher SES groups can be more physically active than those from lower SES groups due to having a better environment and financial outlay for physical activities [39,57]. In [58]'s study, SES was positively associated with sedentary behavior in low-and middle-income countries, whereas there was a negative association between SES and sedentary behavior in high-income countries. Low SES adolescents exhibit more sleep problems, including poor sleep quality and duration [59]. SES is also negatively associated with adolescent mental health problems $[60,61]$.

\subsection{The Current Study}

This study aimed to (1) investigate the differences in adolescents' reports of physical activity, sitting time for study purposes, sitting time for non-study purposes, sleep, stress, sadness/despair, suicidal ideation, and substance use in the year before and during the pandemic; and (2) examine gender differences in the impact of the pandemic, using national representative data pertaining to Korean adolescents collected in 2019 and 2020. These analyses will provide practical and policy implications for supporting the healthy and sustainable lives of adolescents during the COVID-19 pandemic and after.

\section{Materials and Methods}

\subsection{Data and Participants}

This study used data from the 15th (2019) and 16th (2020) Korea Youth Risk Behavior Surveys (KYRBS) conducted by the Ministry of Education, the Ministry of Health and Welfare, and Korea Disease Control and Prevention Agency. The KYRBS is an anonymous, self-reported online survey conducted among middle and high school students to understand health-related behaviors of adolescents such as smoking, drinking, physical activity, and eating habits. This survey is a nationally approved statistical survey and has been conducted annually since 2005 using new samples. The adolescents were interviewed from June to August in 2019 and from August to November in 2020. A stratified cluster method was used for sampling; the primary extraction unit was the school, and the secondary extraction unit was the class. For the primary extraction, sample schools were selected through a permanent random number extraction for each layer. For the secondary extraction, one class was randomly selected by grade from the selected sample school. All students in the class selected as the sample class were surveyed, with students with long-term absences and disabilities excluded. This study merged data from the 15th (2019) and 16th (2020) surveys and used adolescents' responses from both (54,663 observations from the 15th round; 53,375 observations from the 16th) as the analysis sample. 


\subsection{Measures}

The dependent variables were physical activity, sitting time for study purposes, sitting time for non-study purposes, sleep, stress, sadness/despair, drinking, and smoking. Physical activity was assessed with the question "In the past 7 days, on how many days have you done physical activity to the extent that your heart rate increased more than usual or you were short of breath for a total of more than 60 min a day?" The responses were on a scale from 1 to 8 , and ranged from "Not in the last 7 days" $(=1)$ to " 7 days a week" (=8). Sitting time for study purposes and sitting time for non-study purposes were calculated by asking the questions "In the past 7 days, on average, how many hours per day did you spend sitting for study purposes (including watching TV or using a computer for homework or study)?" and "In the past 7 days, on average, how many hours per day did you spend sitting for purposes other than study?"; the responses were measured in minutes.

Sleep was examined via the question "In the past 7 days, do you think the amount of time you have slept was enough to recover from fatigue?" This was measured with the following responses: "Not enough at all" $=1$, "Not enough" $=2$, "Slightly so" $=3$, "Enough" $=4$, and "More than enough" $=5$. Stress and suicidal ideation were measured according to a response of "No" $=0$ or "Yes" $=1$ to the questions "During the past 12 months, have you ever felt so sad or hopeless that you stopped your daily activities for 2 weeks?" and "Have you ever seriously considered suicide in the past 12 months?"

In terms of drinking, respondents answered the question "In the past 30 days, on how many days did you drink at least a glass of alcohol?" by responding "None" $=0$, " $1-2$ days a month" $=1$, " $3-5$ days a month" $=2$, , $6-9$ days a month" $=3$, "10-19 days a month" $=4$, "20-29 days a month" $=5$, or "Daily" $=6$. Smoking was measured by asking "Over the last 30 days, on how many days have you smoked even one cigarette (regular cigarettes, liquid ecigarettes containing nicotine, or cigarette-type e-cigarettes)?" The respondents answered as follows: "None" $=0$, " 2 days" $=1, " 3-5$ days a month" $=2$, " $6-9$ days a month" $=3$, "10-19 days a month" $=4$, "20-29 days a month" $=5$, or "Daily" $=6$. Independent variables included the year $(2019=0,2020=1)$, gender (female $=0$, male $=1)$, age, and household economic status (lower $=1$, middle-lower $=2$, middle $=3$, upper-middle $=4$, upper $=5$ ) .

\subsection{Data Analysis}

We analyzed whether the differences between the mean values of physical activity, sitting time for study purposes, sitting time for non-study purposes, sleep, stress, sadness/despair, drinking, and smoking in 2019 and 2020 were statistically significant through an independent-samples t-test. Next, a regression analysis was performed on these dependent variables, with year as an independent variable and gender, age, and household economic status as confounding factors. Conditional on gender, age, and household economic status, the coefficient estimate of the dummy year was intended to capture the impact of COVID-19. Finally, gender differences in the effects of COVID-19 on the outcomes of interest were estimated by including the interaction term between the year and gender in the regression analysis.

\section{Results}

\subsection{Descriptive Statistics}

In Table 1, the variable means before and during the COVID-19 pandemic are compared using the results of the t-test. Physical activity among adolescents decreased in 2020 relative to 2019. The amount of time spent sitting for study purposes decreased by about 76 min per week in 2020, while the time spent sitting for non-study purposes increased by about $109 \mathrm{~min}$. In 2020, the amount of time the respondents slept enough to recover from fatigue increased slightly and stress decreased slightly. In 2020, sadness/despair and suicidal ideation decreased by $3 \%$ and $2 \%$, respectively. Smoking and drinking decreased slightly in 2020. The ages of the sample ranged from 12 to 18 years, with an average age of 
about 15 years. The gender ratio was 51\% male and $49 \%$ female in 2019 , and $52 \%$ male and $48 \%$ female in 2020 .

Table 1. Descriptive statistics.

\begin{tabular}{|c|c|c|c|c|c|}
\hline & \multicolumn{2}{|c|}{2019} & \multicolumn{2}{|c|}{2020} & \multirow[b]{2}{*}{$t$-Value } \\
\hline & Mean & SD & Mean & SD & \\
\hline Physical activity & 3.02 & 2.13 & 2.90 & 2.12 & $9.48^{* * *}$ \\
\hline Sitting time for study purposes & 687.17 & 417.76 & 611.13 & 380.33 & $31.26^{* * *}$ \\
\hline Sitting time for non-study purposes & 449.44 & 299.31 & 557.99 & 352.79 & $-54.58^{* * *}$ \\
\hline Sleep & 2.67 & 1.12 & 2.95 & 1.13 & $-39.77^{* * *}$ \\
\hline Stress & 3.28 & 0.99 & 3.17 & 0.94 & $19.17^{* * *}$ \\
\hline Sadness/despair & 0.28 & 0.45 & 0.25 & 0.43 & $9.90^{* * *}$ \\
\hline Suicidal ideation & 0.13 & 0.34 & 0.11 & 0.31 & $10.56^{* * *}$ \\
\hline Drinking & 1.26 & 0.78 & 1.19 & 0.67 & $15.60^{* * *}$ \\
\hline Smoking & 1.13 & 0.62 & 1.09 & 0.50 & $11.79^{* * *}$ \\
\hline Household economic status & 3.35 & 0.89 & 3.34 & 0.89 & 1.30 \\
\hline Age (min: 12, max: 18) & 14.97 & 1.78 & 15.10 & 1.76 & $-11.45^{* * *}$ \\
\hline$n$ & \multicolumn{2}{|c|}{54,663 (male $50.9 \%$ ) } & \multicolumn{2}{|c|}{53,375 (male $51.7 \%$ ) } & \\
\hline
\end{tabular}

\subsection{Regression Models}

Table 2 reports the results of the linear regression analysis for physical activity and sitting time. In line with our expectations, there was a statistically significant decrease in physical activity in 2020 compared to $2019(\beta=-0.107, p<0.001)$. Boys were more physically active than girls $(\beta=1.132, p<0.001)$, and physical activity decreased with increasing age $(\beta=-0.107, p<0.001)$. In addition, the higher the household income, the higher the level of physical activity $(\beta=0.088, p<0.001)$. In the coefficient estimates of the interaction term between the year and gender, the effect of the year on physical activity was moderated by gender. Thus, during the COVID-19 pandemic (2020), the physical activity of boys decreased more than that of girls $(\beta=-0.212, p<0.001)$.

Table 2. Linear regression analysis on physical activity and sitting time.

\begin{tabular}{|c|c|c|c|c|c|c|}
\hline & \multicolumn{2}{|c|}{ Physical Activity } & \multicolumn{2}{|c|}{ Sitting Time for Study Purposes } & \multicolumn{2}{|c|}{ Sitting Time for Non-Study Purposes } \\
\hline & $\beta$ (SE) & $\beta$ (SE) & $\beta$ (SE) & $\beta$ (SE) & $\beta$ (SE) & $\beta$ (SE) \\
\hline Year $(2020=1)$ & $-0.107^{* * *}(0.012)$ & $0.003(0.018)$ & $-51.344^{* * *}(1.464)$ & $-113.965^{* * *}(3.327)$ & $109.545^{* * *}(1.982)$ & $114.651^{* * *}(2.853)$ \\
\hline Gender $($ male $=1)$ & $1.132 * * *(0.012)$ & $1.237^{* * *}(0.017)$ & $-75.786^{* * *}(1.466)$ & $-137.834^{* * *}(3.252)$ & $3.280(1.985)$ & $8.156 * *(2.789)$ \\
\hline Age & $-0.107^{* * *}(0.004)$ & $-0.107^{* * *}(0.004)$ & $28.595^{* * *}(0.418)$ & $62.399 * * *(0.660)$ & $-9.776^{* * *}(0.566)$ & $-9.768^{* * *}(0.566)$ \\
\hline $\begin{array}{l}\text { Household } \\
\text { economic status }\end{array}$ & $0.088^{* * *}(0.007)$ & $0.087^{* * *}(0.007)$ & $14.885^{* * *}(0.832)$ & $50.895^{* * *}(1.312)$ & $-29.491^{* * *}(1.126)$ & $-29.522 * * *(1.126)$ \\
\hline Year $X$ gender & & $-0.212 * * *(0.025)$ & & $58.773^{* * *}(4.622)$ & & $-9.864 *(3.964)$ \\
\hline Constant & $3.746^{* * *}(0.062)$ & $3.691(0.062)^{* * *}$ & $19.864^{* *}(7.281)$ & $\begin{array}{c}-346.2000^{* * *} \\
(11.553)\end{array}$ & $692.945^{* * *}(9.856)$ & $690.400 * * *(9.909)$ \\
\hline F statistic & $2439.426^{* * *}$ & $1967.497^{* * *}$ & $2096.413^{* * *}$ & $2577.045^{* * *}$ & $970.166^{* * *}$ & $777.408^{* * *}$ \\
\hline$R^{2}$ & 0.083 & 0.083 & 0.072 & 0.107 & 0.035 & 0.035 \\
\hline$n$ & \multicolumn{6}{|c|}{108,038} \\
\hline
\end{tabular}

Note. $\beta=$ unstandardized coefficient estimates; ${ }^{*} p<0.05 ;{ }^{* *} p<0.01 ;{ }^{* * *} p<0.001$.

Time spent sitting for study purposes decreased by approximately $51 \mathrm{~min}$ per week in 2020 compared to 2019 ( $\beta=-51.344, p<0.001)$. Relative to girls, boys spent approximately $76 \mathrm{~min}$ less sitting down to study per week. Sitting time for studying increased with age $(\beta=28.595, p<0.001)$ and household economic status $(\beta=14.885, p<0.001)$. The coefficient estimates of the interaction term between the year and gender show that sitting time for boys decreased less than that of girls during the pandemic $(\beta=58.773, p<0.001)$.

Sitting for non-study purposes increased by approximately 110 min per week in 2020 compared to $2019(\beta=109.545, p<0.001)$. Sitting time for non-study purposes decreased with age $(\beta=-9.776, p<0.001)$ and with higher household economic status $(\beta=-29.491$, $p<0.001)$. The coefficient estimates of the interaction term between the year and gender 
indicated that the sitting time for non-study purposes among boys increased less than that of girls during the pandemic $(\beta=-9.864, p<0.001)$.

Table 3 shows the results of the linear regression analysis for sleep and stress. Adolescents slept longer in 2020 than in $2019(\beta=0.287, p<0.001)$, and there was a noticeable gender difference in these patterns, with boys sleeping more than girls $(\beta=0.347, p<0.001)$. All adolescents slept less well with age $(\beta=-0.108, p<0.001)$ and were more likely to have adequate sleep with better household economic status $(\beta=0.089, p<0.001)$. The coefficient estimates of the interaction term between the year and gender confirmed that the pandemic increased the hours of sleep for both boys and girls, but increased girls' sleep time more $(\beta=-0.128, p<0.001)$.

Table 3. Linear regression analysis on sleep and stress.

\begin{tabular}{|c|c|c|c|c|}
\hline & \multicolumn{2}{|c|}{ Sleep } & \multicolumn{2}{|c|}{ Stress } \\
\hline & $\beta$ (SE) & $\beta$ (SE) & $\beta$ (SE) & $\beta$ (SE) \\
\hline Year $(2020=1)$ & $0.287^{* * *}(0.007)$ & $0.353^{* * *}(0.010)$ & $-0.119^{* * *}(0.006)$ & $-0.157^{* * *}(0.008)$ \\
\hline Gender $($ male $=1)$ & $0.347^{* * *}(0.007)$ & $0.410 * * *(0.009)$ & $-0.358^{* * *}(0.006)$ & $-0.394^{* * *}(0.008)$ \\
\hline Age & $-0.108^{* * *}(0.002)$ & $-0.108^{* * *}(0.002)$ & $0.044^{* * *}(0.002)$ & $0.044^{* * *}(0.002)$ \\
\hline Household economic status & $0.089^{* * *}(0.004)$ & $0.089^{* * *}(0.004)$ & $-0.117^{* * *}(0.003)$ & $-0.117^{* * *}(0.003)$ \\
\hline Year $X$ gender & & $-0.128^{* * *}(0.013)$ & & $0.073^{* * *}(0.011)$ \\
\hline Constant & $3.810^{* * *}(0.033)$ & $3.777^{* * *}(0.033)$ & $3.200^{* * *}(0.028)$ & $3.219^{* * *}(0.028)$ \\
\hline F statistic & $2186.259 * * *$ & $1769.081^{* * *}$ & $1723.831^{* * *}$ & $1387.742 * * *$ \\
\hline$R^{2}$ & 0.075 & 0.076 & 0.060 & 0.060 \\
\hline$n$ & \multicolumn{4}{|c|}{108,038} \\
\hline
\end{tabular}

Note. $\beta=$ unstandardized coefficient estimates; ${ }^{* * *} p<0.001$.

In general, adolescents were less stressed in 2020 compared to $2019(\beta=-0.119$, $p<0.001)$. The older the respondents were, the more stressed they felt $(\beta=0.044, p<0.001)$, and boys felt less stressed compared to girls $(\beta=-0.358, p<0.001)$. The higher their household economic status, the lower their levels of stress $(\beta=-0.117, p<0.001)$. The coefficient estimates of the interaction term between the year and gender indicated that the pandemic was more effective at reducing stress in girls than in boys $(\beta=0.073, p<0.001)$.

Table 4 displays the results of the binary logistic regression analysis for sadness/despair and suicidal ideation. Overall, among adolescents, sadness/despair decreased in 2020 compared to 2019 ( $\beta=-0.149, p<0.001)$, and boys felt less sadness/despair than girls ( $\beta=-0.617, p<0.001)$. The older the respondents, the more sadness/despair they were likely to feel $(\beta=0.060, p<0.001)$, but the better their household economic status, the less the likelihood of sadness/despair $(\beta=-0.156, p<0.001)$. The coefficient estimates of the interaction term between the year and gender confirmed that the pandemic decreased sadness/despair more effectively among girls than boys $(\beta=0.056, p<0.001)$.

Suicidal ideation among adolescents decreased in 2020 compared to $2019(\beta=-0.237$, $p<0.001)$. Boys had lower tendencies toward suicidal ideation than girls $(\beta=-0.681$, $p<0.001)$. The higher the age $(\beta=-0.013, p<0.05)$ and household economic status $(\beta=-0.273, p<0.001)$, the lower the propensity for suicidal ideation. The interaction term between the year and gender indicated that suicidal ideation decreased less in boys than in girls in $2020(\beta=0.087, p<0.05)$.

Table 5 shows the results of the linear regression analysis for drinking and smoking. Adolescents generally decreased their drinking $(\beta=-0.077, p<0.001)$ and smoking $(\beta=-0.045, p<0.001)$ in 2020 compared to 2019 , and boys were more likely to drink $(\beta=0.085, p<0.001)$ and smoke $(\beta=0.106, p<0.001)$ than girls. Both drinking $(\beta=0.066, p<0.001)$ and smoking were more likely to increase with age $(\beta=0.044$, $p<0.001)$, whereas higher household economic status decreased both drinking $(\beta=-0.009$, $p<0.001)$ and smoking $(\beta=-0.004, p<0.05)$. The coefficient estimates of the interac- 
tion term between the year and gender indicated that the pandemic reduced drinking $(\beta=-0.032, p<0.001)$ and smoking $(\beta=-0.053, p<0.001)$ more in boys than in girls.

Table 4. Logistic regression analysis on sadness/despair and suicidal ideation.

\begin{tabular}{|c|c|c|c|c|}
\hline & \multicolumn{2}{|c|}{ Sadness/Despair } & \multicolumn{2}{|c|}{ Suicidal Ideation } \\
\hline & $\beta$ (SE) & $\beta$ (SE) & $\beta$ (SE) & $\beta$ (SE) \\
\hline Year $(2020=1)$ & $-0.149^{* * *}(0.014)$ & $-0.174^{* * *}(0.019)$ & $-0.203^{* * *}(0.019)$ & $-0.237^{* * *}(0.024)$ \\
\hline Gender $($ male $=1)$ & $-0.617^{* * *}(0.014)$ & $-0.644^{* * *}(0.020)$ & $-0.681 * * *(0.020)$ & $-0.721^{* * *}(0.027)$ \\
\hline Age & $0.060^{* * *}(0.004)$ & $0.060^{* * *}(0.004)$ & $-0.013 *(0.005)$ & $-0.013 *(0.005)$ \\
\hline Household economic status & $-0.156^{* * *}(0.008)$ & $-0.156^{* * *}(0.008)$ & $-0.273^{* * *}(0.011)$ & $-0.273^{* * *}(0.011)$ \\
\hline Year X gender & & $0.056^{* * *}(0.028)$ & & $0.087 *(0.039)$ \\
\hline Constant & $-1.048^{* * *}(0.070)$ & $-1.036^{* * *}(0.070)$ & $-0.522^{* * *}(0.094)$ & $-0.506^{* * *}(0.094)$ \\
\hline$\chi^{2}(\mathrm{df})$ & $2822.677(4)^{* * *}$ & $2826.613(5)^{* * *}$ & $2076.946(4)^{* * *}$ & $2081.937(5)^{* * *}$ \\
\hline Nagelkerke $R^{2}$ & 0.038 & 0.038 & 0.037 & 0.037 \\
\hline$n$ & \multicolumn{4}{|c|}{108,038} \\
\hline
\end{tabular}

Note. $\beta=$ unstandardized coefficient estimates; ${ }^{*} p<0.05 ;{ }^{* * *} p<0.001$.

Table 5. Linear regression analysis on drinking and smoking.

\begin{tabular}{|c|c|c|c|c|}
\hline & \multicolumn{2}{|c|}{ Drinking } & \multicolumn{2}{|c|}{ Smoking } \\
\hline & $\beta$ (SE) & $\beta$ (SE) & $\beta$ (SE) & $\beta$ (SE) \\
\hline Year $(2020=1)$ & $-0.077^{* * *}(0.004)$ & $-0.060(0.006)^{* * *}$ & $-0.045^{* * *}(0.003)$ & $-0.018^{* * *}(0.005)$ \\
\hline Gender $($ male $=1)$ & $0.085^{* * *}(0.004)$ & $0.101(0.006)^{* * *}$ & $0.106^{* * *}(0.003)$ & 0.132 *** $(0.005)$ \\
\hline Age & $0.066^{* * *}(0.001)$ & $0.066(0.001) * * *$ & $0.044^{* * *}(0.001)$ & $0.044^{* * *}(0.001)$ \\
\hline Household economic status & $-0.009^{* * *}(0.002)$ & $-0.010(0.002)^{* * *}$ & $-0.004 *(0.002)$ & $-0.005 *(0.002)$ \\
\hline Year X gender & & $-0.032(0.009) * * *$ & & $-0.053^{* * *}(0.007)$ \\
\hline Constant & $0.251^{* * *}(0.022)$ & $0.242(0.022) * * *$ & $0.439 * * *(0.017)$ & $0.425^{* * *}(0.017)$ \\
\hline F statistic & $901.874 * * *$ & $724.358^{* * *}$ & $821.410 * * *$ & $669.699^{* * *}$ \\
\hline$R^{2}$ & 0.032 & 0.032 & 0.030 & 0.030 \\
\hline$n$ & \multicolumn{4}{|c|}{108,038} \\
\hline
\end{tabular}

Note. $\beta=$ unstandardized coefficient estimates; ${ }^{*} p<0.05 ;{ }^{* * *} p<0.001$.

\section{Discussion}

This study analyzed how adolescents' physical activity, sitting time, sleep, stress, sadness/despair, drinking, and smoking changed in 2020, during the COVID-19 pandemic, in comparison to pre-outbreak levels in 2019. The findings indicate that the COVID19 pandemic can both negatively and positively affect adolescents depending on their demographic characteristics. Furthermore, we observed that the impact of the COVID-19 pandemic on adolescents was gender-specific.

Physical activity decreased during the pandemic due to the decline in social and outdoor activities (e.g., the cancellation of youth sports, a decline in active commuting, restrictions on visiting friends) and school closures and social distancing [21,48]. Decreased physical activity may lead to unhealthy weight gain and increased screen time [8,9] and may decrease opportunities to acquire social skills, such as perseverance and teamwork, through sports activities [7-9]. The decrease in physical activity over the pandemic was more prominent among boys than girls. Given that boys were more physically active than girls prior to the pandemic, the restrictions on physical activity had a greater effect on them [48].

The time spent sitting for study purposes decreased among Korean adolescents during the pandemic, while sitting for other reasons increased. The transition of school classes to online platforms due to COVID-19 may have reduced adolescents' motivation to learn. In addition, learning through private education may have also decreased due to closures 
or the limited operation of private education institutions during the pandemic, which the vast majority of Korean students are enrolled in. Given that people's leisure-related screen time increased during the pandemic [7,62], the decrease in time studying due to COVID-19 may have led to an increase in leisure activities using electronic devices, such as watching TV, online gaming, using social networking services (SNSs), and instant messaging. The increase in sitting time for non-study purposes (about $109 \mathrm{~min}$ ) was about two times greater than the decrease in sitting time for study purposes (about $51 \mathrm{~min}$ ). This may have been because, before COVID-19, time invested in study and time spent on other activities (e.g., walking, using transportation, and shopping) was replaced by sitting time for non-study purposes.

This phenomenon was even more pronounced among female students. Although female students usually spend more time on their studies than their male counterparts, they are more vulnerable during crisis situations, such as the pandemic, in terms of learning. It has been observed that during adolescence, girls are more interpersonally oriented than boys [35] and tend to participate more actively in online activities such as SNS and instant messaging $[63,64]$. Therefore, a psychological reaction of using online social activity to compensate for reduced peer relations due to measures such as school closure and social distancing may have played a role in increasing the time girls spent sitting apart from studying.

Somewhat counterintuitive to our general expectation, the COVID-19 pandemic played a positive role in adolescent mental health in terms of stress, sadness/despair, and suicidal ideation and substance use. Over the course of 2020, adolescents slept longer, and their levels of stress, sadness /despair, suicidal ideation, drinking, and smoking decreased. These results contrast with previous studies that found that the pandemic had a negative impact on adolescents' mental health, including increases in distress, anxiety, depression, stress, and loneliness $[14,15,65,66]$.

These differences may have been due to the different socio-cultural backgrounds of the countries where those studies were conducted. For example, in Canada [14] and Ireland [66], adolescents have less academic burden than those in Korea and spend more time with their families over the weekends. Therefore, the decrease in study time and increase in time spent with families due to the COVID-19 lockdown would have been greater for Korean adolescents, and this may have had a different effect on their mental health compared to adolescents from other countries.

However, the results in this study are in the same vein as studies that have focused on the positive aspects of the increase in stay-at-home time due to the pandemic [4,29]. School closures and social distancing mean that adolescents may experience less academic and social pressure [67], and an increase in time spent with parents may improve their familial relationships and provide them with emotional stability [28].

The pandemic had a more positive effect on girls in terms of sleep, stress, sadness/despair, and suicidal ideation. For instance, during the pandemic, girls' sleep increased, and their levels of stress, sadness/despair, and suicidal ideation decreased significantly compared to boys. Given that girls slept less than boys prior to the pandemic, and that stress, sadness/despair, and suicidal ideation were higher among girls, a physical release from a stressful situation during COVID-19 would have provided them with greater rest, and they may have gained greater comfort and peace of mind due to increased interactions with family at home.

During the pandemic, drinking and smoking decreased more among boys. Given that boys drink and smoke more than girls, it is likely that boys experienced more restrictions on drinking and smoking during the pandemic. Adolescents mainly use substances with peers, meaning that school closures and social distancing may have physically prevented adolescents from using substances [20]. Moreover, considering that time spent with parents at home increased, parental interest and support may have reduced substance use [30]. Parents may have also reduced risky behaviors by closely monitoring their children during the pandemic [29]. 
We also identified a gender disparity in adolescents' lives. As in previous studies, boys had more physical activity than girls $[38,39]$. The reason that boys had higher sitting time for non-study purposes than girls may have been because boys prefer leisure through screens, such as watching television and online gaming, compared to girls [41]. Girls' reduced amount of sufficient sleep in comparison to boys aligns with the results of previous studies on poor sleep quality and short sleep duration among girls [42-44]. The result showing that girls were more vulnerable to stress, sadness/despair, and suicidal ideation than boys supports existing research findings that more internalizing problems appear among girls during adolescence [35]. Boys' increased drinking and smoking compared to girls is also consistent with prior studies that found that boys have higher rates of substance use than girls during adolescence [36,37].

Age was positively associated with sitting time for study purposes and negatively associated with physical activity and sitting time for non-study purposes. This may have been because the academic burden of Korean adolescents increases as they get older. It may also have been reflective of the negative association between age and sleep, the positive association between age and stress, and the positive association between age and sadness/despair. However, the decrease in suicidal ideation with increasing age indicates that adolescents' coping abilities develop further so that academic burden does not lead to suicide.

\subsection{Implications for Policy and Practice}

This study presented both the positive and negative effects of the COVID-19 pandemic on adolescents. It now considers practical policy implications for ensuring the sustainability of healthy lifestyles among adolescents during the pandemic and after it. First, during the pandemic, reductions in physical activity among adolescents can impair their health and social development, meaning countermeasures are needed. Given that time sitting for purposes other than studying has increased, we need to develop online platforms that encourage healthy lifestyle choices. For instance, yoga studios, dance schools, and fitness gyms providing remote classes can help adolescents be more active and stay connected with friends [68]. If more digital health technologies for exercise, such as apps that support self-regulation and online social networking communities for people interested in specific activities, are developed and made available to adolescents, they can spend their time at home in a healthier manner.

Second, the counterintuitive outcomes-increased sleep and improved mental health in terms of stress, sadness/despair, and suicidal ideation-provide evidence that the pre-pandemic lives of adolescents placed immense mental strain on them, leaving them vulnerable to mental health conditions. In Korea, competition for college entrance exams is fierce, and private education is added onto regular school classes. According to the 2018 Youth Statistics [69], 70.5\% of youth are privately educated. Most students go to a private academy after school during the week and do their homework until late at night. Since many students go to a private academy for studying, even on weekends, they do not have enough time for leisure activities or to spend with their parents. In schools, academics-oriented classes are conducted to improve students' grades, and education related to arts, sports, creativity, and character is relatively lacking. As parents place the greatest emphasis on school performance in their children's education, they tend to force their children to study and neglect other aspects (e.g., conversation with their children, leisure activities together, character building). Therefore, the closure of private academies due to COVID-19 and the increase in time spent with parents at home would have been a time of mental rest for adolescents, offering them a chance to get away from their busy and high-pressure lives.

If social life reverts to what it was before the pandemic, the mental health (stress, sadness/despair, and suicidal ideation) of adolescents could get worse again. In the postpandemic era, a fundamental change in education policy is needed to alleviate competition for college entrance exams and reduce the pressures of private education to ensure adolescents lead mentally healthier lives. Parents should not force their children to study 
excessively and should strive to interact with their children (e.g., sufficient conversations with children and leisure activities together) even after the pandemic is over. Schools should reduce the academic-oriented curriculum and increase classes that promote sports, volunteer activities, cultural activities, and leisure activities. This curriculum structure will enable students to grow physically, emotionally, and intellectually in a balanced way. Given that girls are more vulnerable to mental health problems than boys during adolescence, and that girls' mental health has improved more during the pandemic, parents, educators, and practitioners should pay more attention to the mental health of girls after COVID-19.

Third, the decline in drinking and smoking is partly because of fewer opportunities to meet friends to do these things with during the pandemic, but it may also be because parents are taking more care in managing their children's risky behaviors as they spend more time at home. Therefore, even after the pandemic is over, parents should make an effort to prevent risky behaviors in their children by actively interacting with them. Especially given that boys are more vulnerable to drinking and smoking, parents and teachers should remain alert and intervene to ensure that substance use in boys does not increase again after the pandemic. Adolescents' smoking and drinking may increase rapidly after the pandemic is over, and it is necessary to strengthen the crackdown on selling alcohol and tobacco to youth and promote national education to prevent adolescents' smoking and drinking.

\subsection{Limitations and Future Directions}

As this study used secondary data, there were limitations on what areas of adolescents' lives could be analyzed. In the case of time spent sitting apart from studying, it is necessary to analyze what the teenagers spent their time doing (e.g., using SNSs, watching TV, gaming, reading books, doing art) in more detail. In the case of mental health, variables accounting for representative mental health measures, such as depressive symptoms and anxiety, should be included. As variables were measured with a single item in this study, measurement validity may have been compromised. Furthermore, it is important to investigate how much time spent with parents increased and what activities adolescents did with their parents during that time (e.g., talking, gaming, watching TV, eating meals).

\section{Conclusions}

This study examined the impact of the COVID-19 pandemic on various areas of adolescents' lives, with a particular focus on gender differences, by comparing data from 2019 and 2020. We observed that the pandemic had positive and negative effects on different areas of young people's lives and that these effects were largely moderated by gender differences. In the absence of empirical studies on the effects of the pandemic on adolescents, our study serves as a basis for policies and practices that can improve the sustainability of adolescents' healthy lives during the pandemic and after it is over. During the pandemic, action plans to promote adolescents' physical activity need to be prepared. A change in education policy and management of the mental health (stress, sadness/despair, and suicidal ideation) of adolescents is necessary to prevent adolescents mental health from worsening again. In addition, proper attention and intervention from parents, teachers, and practitioners is needed to prevent another increase in substance use among adolescents after the pandemic is over.

Author Contributions: Conceptualization, S.Y. and C.C.; methodology, S.Y. and C.C.; software, S.Y.; validation, S.Y. and C.C.; formal analysis, S.Y.; investigation, S.Y.; resources, S.Y.; data curation, S.Y.; writing — original draft preparation, S.Y.; writing—review and editing, C.C.; visualization, S.Y.; supervision, C.C.; project administration, S.Y. Both authors have read and agreed to the published version of the manuscript.

Funding: This research received no external funding.

Institutional Review Board Statement: Not applicable.

Informed Consent Statement: Informed consent was obtained from all subjects involved in the study. 


\section{Data Availability Statement: Not applicable.}

Conflicts of Interest: The authors declare no conflict of interest.

\section{References}

1. Riiser, K.; Helseth, S.; Haraldstad, K.; Torbjørnsen, A.; Richardsen, K.R. Adolescents' health literacy, health protective measures, and health-related quality of life during the COVID-19 pandemic. PLoS ONE 2020, 15, e238161. [CrossRef]

2. Castagnoli, R.; Votto, M.; Licari, A.; Brambilla, I.; Bruno, R.; Perlini, S.; Rovida, F.; Baldanti, F.; Marseglia, G.L. Severe acute respiratory syndrome coronavirus 2 (SARS-CoV-2) infection in children and adolescents: A systematic review. JAMA Pediatr. 2020, 174, 882-889. [CrossRef] [PubMed]

3. Walker, D.M.; Tolentino, V.R. COVID-19: The impact on pediatric emergency care. Pediatr. Emerg. Med. Pract. 2020, $17,1-27$.

4. Isumi, A.; Doi, S.; Yamaoka, Y.; Takahashi, K.; Fujiwara, T. Do suicide rates in children and adolescents change during school closure in Japan? The acute effect of the first wave of COVID-19 pandemic on child and adolescent mental health. Child Abus. Negl. 2020, 110, 104680. [CrossRef]

5. Orben, A.; Tomova, L.; Blakemore, S.-J. The effects of social deprivation on adolescent development and mental health. Lancet Child Adolesc. Health 2020, 4, 634-640. [CrossRef]

6. Becker, S.P.; Gregory, A.M. Editorial perspective: Perils and promise for child and adolescents sleep and associated psychopathology during the COVID-19 pandemic. J. Child Psychol. Psychiatry 2020, 61, 757-759. [CrossRef] [PubMed]

7. Gupta, T.; Nebhinani, N. Impact of COVID-19 pandemic on child and adolescent mental health. J. Indian Assoc. Child Adolesc. Ment. Health 2020, 16, 1-16.

8. Chaabane, S.; Doraiswamy, S.; Chaabna, K.; Mamtani, R.; Cheema, S. The impact of COVID-19 school closure on child and adolescent health: A rapid systematic review. Children 2021, 8, 415. [CrossRef] [PubMed]

9. Franckle, R.; Adler, R.; Davison, K. Accelerated weight gain among children during summer versus school year and related racial/ethnic disparities: A systematic review. Prev. Chronic Dis. 2014, 11, E101. [CrossRef] [PubMed]

10. Ren, H.; He, X.; Bian, X.; Shang, X.; Liu, J. The protective roles of exercise and maintenance of daily living routines for Chinese adolescents during the COVID-19 quarantine period. J. Adolesc. Health 2021, 68, 35-42. [CrossRef]

11. Becker, S.P.; Dvorsky, M.R.; Breaux, R.; Cusick, C.N.; Taylor, K.P.; Langberg, J.M. Prospective examination of adolescent sleep patterns and behaviors before and during COVID-19. Sleep 2021,1-11. [CrossRef]

12. Kapetanovic, S.; Gurdal, S.; Ander, B.; Sorbring, E. Reported changes in adolescent psychosocial functioning during the COVID-19 outbreak. Adolescents 2021, 1, 10-20. [CrossRef]

13. Saurabh, K.; Ranjan, S. Compliance and psychological impact of quarantine in children and adolescents due to COVID-19 pandemic. Indian J. Pediatr. 2020, 87, 532-536. [CrossRef]

14. Ellis, W.E.; Dumas, T.M.; Forbes, L.M. Physically isolated but socially connected: Psychological adjustment and stress among adolescents during the initial COVID-19 crisis. Can. J. Behav. Sci. 2020, 52, 177-187. [CrossRef]

15. Xie, X.; Xue, Q.; Zhou, Y.; Zhu, K.; Liu, Q.; Zhang, J.; Song, R. Mental health status among children in home confinement during the coronavirus disease 2019 outbreak in Hubei Province, China. JAMA Pediatr. 2020, 174, 898-900. [CrossRef] [PubMed]

16. Dumas, T.M.; Ellis, W.; Litt, D.M. What does adolescent substance use look like during the COVID-19 pandemic? Examining changes in frequency, social contexts, and pandemic-related predictors. J. Adolesc. Health 2020, 67, 354-361. [CrossRef]

17. Souza, L.D.D.M.; Molina, M.L.; da Silva, R.A.; Jansen, K. History of childhood trauma as risk factors to suicide risk in major depression. Psychiatry Res. 2016, 246, 612-616. [CrossRef]

18. Guessoum, S.B.; Lachal, J.; Radjack, R.; Carretier, E.; Minassian, S.; Benoit, L.; Moro, M.R. Adolescent psychiatric disorders during the COVID-19 pandemic and lockdown. Psychiatry Res. 2020, 291, 113264. [CrossRef] [PubMed]

19. Volkow, N.D. Collision of the COVID-19 and addiction epidemics. Ann. Intern. Med. 2020, 173, 61-62. [CrossRef]

20. Kuntsche, E.; Knibbe, R.; Gmel, G.; Engels, R. Why do young people drink? A review of drinking motives. Clin. Psychol. Rev. 2005, 25, 841-861. [CrossRef]

21. Chaffee, B.W.; Cheng, J.; Couch, E.T.; Hoeft, K.S.; Halpern-Felsher, B. Adolescents' substance use and physical activity before and during the COVID-19 pandemic. JAMA Pediatr. 2021, 175, 715-722. [CrossRef] [PubMed]

22. Carballo, J.J.; Llorente, C.; Kehrmann, L.; Flamarique, I.; Zuddas, A.; Purper-Ouakil, D.; Hoekstra, P.J.; Coghill, D.; Schulze, U.M.E.; Dittmann, R.W.; et al. Psychosocial risk factors for suicidality in children and adolescents. Eur. Child Adolesc. Psychiatry 2020, 29, 759-776. [CrossRef] [PubMed]

23. Fortgang, R.G.; Wang, S.B.; Millner, A.J.; Reid-Russell, A.; Beukenhorst, A.L.; Kleiman, E.M.; Bentley, K.H.; Zuromski, K.L.; Al-Suwaidi, M.; Bird, S.A.; et al. Increase in Suicidal Thinking During COVID-19. Clin. Psychol. Sci. 2021, 9, 482-488. [CrossRef]

24. Clay, R.; Knibbs, J.; Joseph, S. Measurement of posttraumatic growth in young people: A review. Clin. Child Psychol. Psychiatry 2009, 14, 411-422. [CrossRef] [PubMed]

25. Milam, J.E.; Ritt-Olson, A.; Unger, J. Posttraumatic growth among adolescents. J. Adolesc. Res. 2004, 19, 192-204. [CrossRef]

26. Sleijpen, M.; Haagen, J.; Mooren, T.; Kleber, R.J. Growing from experience: An exploratory study of posttraumatic growth in adolescent refugees. Eur. J. Psychotraumatol. 2016, 7, 28698. [CrossRef] [PubMed]

27. Calhoun, L.G.; Tedeschi, R.G. The Foundations of Posttraumatic Growth: An Expanded Framework. In Handbook of Posttraumatic Growth: Research and Practice; Calhoun, L.G., Tedeschi, R.G., Eds.; Erlbaum: Mahwah, NJ, USA, 2006; pp. 3-23. 
28. Richter, L. The effects of the COVID-19 pandemic on the risk of youth substance use. J. Adolesc. Health 2020, 67, 467-468. [CrossRef] [PubMed]

29. Szlyk, H.S.; Berk, M.; Peralta, A.O.; Miranda, R. COVID-19 takes adolescent suicide prevention to less charted territory. J. Adolesc. Health 2020, 67, 161-163. [CrossRef]

30. Courtney, D.; Watson, P.; Battaglia, M.; Mulsant, B.H.; Szatmari, P. COVID-19 impacts on child and youth anxiety and depression: Challenges and opportunities. Can. J. Psychiatry 2020, 65, 688-691. [CrossRef] [PubMed]

31. Hwang, S.; Kim, N. A Study on the Quality of Life of Youth and Support Measures to Achieve the Sustainable Development Goals (SDGs). In National Youth Policy Institute Research Report16-R01; National Youth Policy Institute: Sejong, Korea, 2016.

32. Dooley, D.G.; Bandealy, A.; Tschudy, M.M. Low-income children and coronavirus disease 2019 (COVID-19) in the US. JAMA Pediatr. 2020, 174, 922-923. [CrossRef] [PubMed]

33. Martin, E.G.; Sorensen, L.C. Protecting the health of vulnerable children and adolescents during COVID-19-related K-12 school closures in the US. JAMA Health Forum 2020, 1, e200724. [CrossRef]

34. Nolen-Hoeksema, S. Gender differences in depression. J. Am. Psychol. Soc. 2001, 10, 173-176. [CrossRef]

35. Hankin, B.L.; Mermelstein, R.; Roesch, L. Sex differences in adolescent depression: Stress exposure and reactivity models. Child Dev. 2007, 78, 279-295. [CrossRef]

36. Kuhn, C. Emergence of sex differences in the development of substance use and abuse during adolescence. Pharmacol. Ther. 2015, 153, 55-78. [CrossRef] [PubMed]

37. Leadbeater, B.J.; Kuperminc, G.P.; Blatt, S.J.; Hertzog, C. A multivariate model of gender differences in adolescents' internalizing and externalizing problems. Dev. Psychol. 1999, 35, 1268-1282. [CrossRef] [PubMed]

38. Ishii, K.; Shibata, A.; Adachi, M.; Nonoue, K.; Oka, K. Gender and grade differences in objectively measured physical activity and sedentary behavior patterns among Japanese children and adolescents: A cross-sectional study. BMC Public Health 2015, 15, 1254 [CrossRef] [PubMed]

39. Kumar, B.; Robinson, R.; Till, S. Physical activity and health in adolescence. Clin. Med. 2015, 15, 267-272. [CrossRef] [PubMed]

40. Iannotti, R.J.; Wang, J. Trends in physical activity, sedentary behavior, diet, and BMI among US adolescents, 2001-2009. Pediatrics 2013, 132, 606-614. [CrossRef]

41. Prince, S.A.; Roberts, K.C.; Melvin, A.; Butler, G.P.; Thompson, W. Gender and education differences in sedentary behaviour in Canada: An analysis of national cross-sectional surveys. BMC Public Health 2020, 20, 1-17. [CrossRef]

42. Galland, B.C.; Gray, A.R.; Penno, J.; Smith, C.; Lobb, C.; Taylor, R.W. Gender differences in sleep hygiene practices and sleep quality in New Zealand adolescents aged 15 to 17 years. Sleep Health 2017, 3, 77-83. [CrossRef]

43. Jakobsson, M.; Josefsson, K.; Jutengren, G.; Sandsjö, L.; Högberg, K. Sleep duration and sleeping difficulties among adolescents: Exploring associations with school stress, self-perception and technology use. Scand. J. Caring Sci. 2018, 33, 197-206. [CrossRef] [PubMed]

44. Organek, K.D.M.; Taylor, D.J.; Petrie, T.; Martin, S.; Greenleaf, C.; Dietch, J.; Ruiz, J.M. Adolescent sleep disparities: Sex and racial/ethnic differences. Sleep Health 2015, 1, 36-39. [CrossRef]

45. Shanahan, L.; Steinhoff, A.; Bechtiger, L.; Murray, A.L.; Nivette, A.; Hepp, U.; Ribeaud, D.; Eisner, M. Emotional distress in young adults during the COVID-19 pandemic: Evidence of risk and resilience from a longitudinal cohort study. Psychol. Med. 2020, 23, 1-10. [CrossRef] [PubMed]

46. Cui, Y.; Zhu, Q.; Lou, C.; Gao, E.; Cheng, Y.; Zabin, L.S.; Emerson, M.R. Gender differences in cigarette smoking and alcohol drinking among adolescents and young adults in Hanoi, Shanghai, and Taipei. J. Int. Med Res. 2018, 46, 5257-5268. [CrossRef] [PubMed]

47. Hoffmann, J.P. Extracurricular activities, athletic participation, and adolescent alcohol use: Gender-differentiated and schoolcontextual effects. J. Health Soc. Behav. 2006, 47, 275-290. [CrossRef]

48. Pagoto, S.L.; Conroy, D.E. Revitalizing adolescent health behavior after the COVID-19 pandemic. JAMA Pediatr. 2021. [CrossRef]

49. Cho, D.; Kim, J. The impact of the COVID-19 pandemic on the domestic economy and future challenges. J. Humanit. Soc. Sci. 21 2020, 11, 2597-2612. [CrossRef]

50. Choi, J. The Effects of COVID-19 pandemic on the mental health of the general public and children and adolescents and supporting measures. J. Korean Neuropsychiatr. Assoc. 2021, 60, 2-10. [CrossRef]

51. Chung, I.; Lee, S.; Kang, H. Changes in Children's Everyday Life and Emotional Conditions Due to the COVID-19 Pandemic. J. Korean Soc. Child Welf. 2020, 69, 59-90. [CrossRef]

52. Allison, K.R.; Adlaf, E.M.; Dwyer, J.J.M.; Lysy, D.C.; Irving, H.M. The decline in physical activity among adolescent students. Can. J. Public Health 2007, 98, 97-100. [CrossRef] [PubMed]

53. Harding, S.K.; Page, A.S.; Falconer, C.; Cooper, A.R. Longitudinal changes in sedentary time and physical activity during adolescence. Int. J. Behav. Nutr. Phys. Act. 2015, 12, 44. [CrossRef]

54. Colrain, I.M.; Baker, F. Changes in sleep as a function of adolescent development. Neuropsychol. Rev. 2011, 21, 5-21. [CrossRef]

55. Schwarz, S.W. Adolescent Mental Health in the United States: Facts for Policymakers; National Center for Child in Poverty: New York, NY, USA, 2009.

56. Yeh, C.J. Age, acculturation, cultural adjustment, and mental health symptoms of Chinese, Korean, and Japanese immigrant youths. Cult. Divers. Ethn. Minor. Psychol. 2003, 9, 34-48. [CrossRef]

57. Stalsberg, R.; Pedersen, A.V. Effects of socioeconomic status on the physical activity in adolescents: A systematic review of the evidence. Scand. J. Med. Sci. Sports 2010, 20, 368-383. [CrossRef] [PubMed] 
58. Mielke, G.I.; Brown, W.J.; Nunes, B.P.; da Silva, I.C.M.; Hallal, P.C. Socioeconomic correlates of sedentary behavior in adolescents: Systematic review and meta-analysis. Sports Med. 2017, 47, 61-75. [CrossRef] [PubMed]

59. Doane, L.D.; Breitenstein, R.S.; Beekman, C.; Clifford, S.; Smith, T.J.; Lemery-Chalfant, K. Early life socioeconomic disparities in children's sleep: The mediating role of the current home environment. J. Youth Adolesc. 2019, 48, 56-70. [CrossRef] [PubMed]

60. Weinberg, D.; Stevens, G.W.J.M.; Duinhof, E.L.; Finkenauer, C. Adolescent socioeconomic status and mental health inequalities in the Netherlands, 2001-2017. Int. J. Environ. Res. Public Health 2019, 16, 3605. [CrossRef]

61. Wight, R.G.; Botticello, A.L.; Aneshensel, C.S. Socioeconomic context, social support, and adolescent mental health: A multilevel investigation. J. Youth Adolesc. 2006, 35, 109-120. [CrossRef]

62. Kar, S.K.; Arafat, S.M.Y.; Sharma, P.; Dixit, A.; Marthoenis, M.; Kabir, R. COVID-19 pandemic and addiction: Current problems and future concerns. Asian J. Psychiatry 2020, 51, 102064. [CrossRef] [PubMed]

63. Kim, H.M.; Shin, S.H. Comparison of Gender Factors Affecting Middle School Students' Smartphone Addiction. J. Korean Acad. Psychiatr. Ment. Health Nurs. 2015, 24, 145-155. [CrossRef]

64. Mihara, S.; Osaki, Y.; Nakayama, H.; Sakuma, H.; Ikeda, M.; Itani, O.; Kaneita, Y.; Kanda, H.; Ohida, T.; Higuchi, S. Internet use and problematic internet use among adolescents in Japan: A nationwide representative survey. Addict. Behav. Rep. 2016, 4, 58-64. [CrossRef] [PubMed]

65. De Miranda, D.M.; Athanasio, B.d.S.; Oliveira, A.C.S.; Simoes-e-Silva, A.C. How is COVID-19 pandemic impacting mental health of children and adolescents? Int. J. Disaster Risk Reduct. 2020, 51, 101845. [CrossRef]

66. O'Sullivan, K.; Clark, S.; McGrane, A.; Rock, N.; Burke, L.; Boyle, N.; Joksimovic, N.; Marshall, K. A Qualitative Study of Child and Adolescent Mental Health during the COVID-19 Pandemic in Ireland. Int. J. Environ. Res. Public Health 2021, $18,1062$. [CrossRef] [PubMed]

67. Hoekstra, P.J. Suicidality in children and adolescents: Lessons to be learned from the COVID-19 crisis. Eur. Child Adolesc. Psychiatry 2020, 29, 737-738. [CrossRef] [PubMed]

68. Murlidar, K.; The Brighter Side of the Lockdown. The Hindu. 2020. Available online: https://www.thehindu.com/opinion/ open-page/the-brighter-side-of-the-lockdown/article31376457.ece (accessed on 13 June 2021).

69. Statistics Korea \& Ministry of Gender Equality and Family. 2018 Youth Statistics; Statistics Korea: Daejeon, Korea, 2018. 